\title{
Blaue Augen verraten erhöhtes Melanomrisiko
}

\begin{abstract}
Blond, blauäugig, blass - dass diese Eigenschaften mit einem erhöhten Melanomrisiko korrelieren, ist schon lange bekannt. Bei der Analyse des Erbguts von mehr als 3000 Probanden haben US-Forscher der University of Colorado in Aurora (USA) jetzt herausgefunden, warum die Augenfarbe ein erhöhtes Risiko signalisiert, am Melanom zu erkranken.
\end{abstract}

- Die Forscher analysierten die Gene von 3187 US-Amerikanern europäischer Abstammung, die unter Vitiligo litten. Bei dieser Hautkrankheit kommt es zu Pigmentstörungen in Form weißer Flecken.

Die Wissenschaftler entdeckten 13 Genvarianten, die das Risiko für Vitiligo - auch Weißfleckenkrankheit genannt erhöhen. Zugleich stellten sie fest, dass Menschen mit blauen oder grauen Augen unter den Vitiligopatienten signifikant unterrepräsentiert waren. Nur $27 \%$ der Vitiligopatienten hatten blaue oder graue Augen. Bei der untersuchten Bevölkerungsgruppe, den US-Einwohnern mit europäischen Wurzeln, liegt der Anteil der Blau- und Grauäugigen bei $52 \%$.

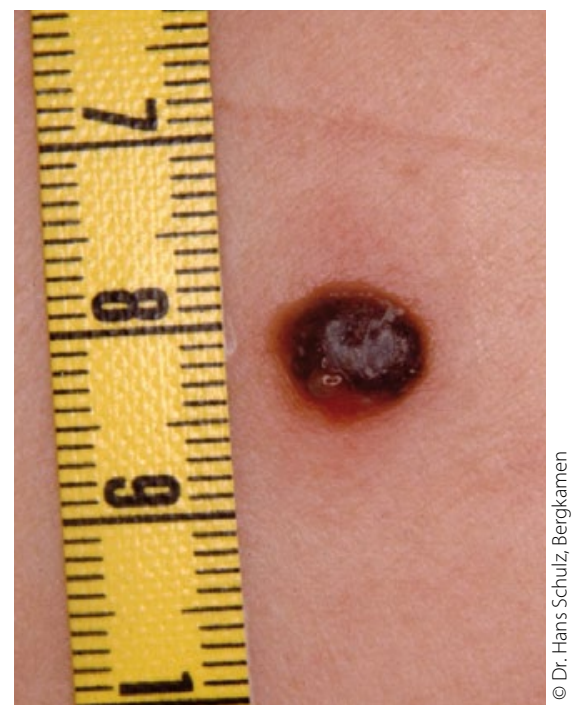

Malignes noduläres Melanom.

Der Zusammenhang mit der Augenfarbe ist eindeutig: Jene Genvarianten, die für ein niedriges Vitiligorisiko stehen, sind zugleich für die Farben grau und blau verantwortlich. Dunkle Augen hingegen sind mit einem höheren Vitiligorisiko verbunden. Wer zu einer Vitiligo tendiert, bekommt seltener ein Melanom. Ein niedriges Vitiligorisko hingegen ist mit einem erhöhten Melanomrisiko assoziiert.

\section{Kommentar}

Genetisch gesehen sind Vitiligo und Melanom Gegenspieler, sagen die Autoren. Eine Genvariante erhöht die Gefahr der einen Hautkrankheit und senkt die der anderen. Vitiligo ist eine Autoimmunkrankheit, bei der das Abwehrsystem eines Menschen die eigenen Pigmentzellen attackiert. Die Autoren vermuten, dass Vitiligo eine Überaktivität eines Prozesses darstellt, bei dem das Immunsystem entartete Hautkrebszellen sucht und zerstört. Zu dieser These passt auch das gehäufte Auftreten von anderen Autoimmunkrankheiten wie Diabetes Typ 1 oder rheumatoide Arthritis bei Vitiligopatienten. Deren Verwandte haben ebenfalls ein erhöhtes Risiko für diese Autoimmunkrankheiten, selbst wenn sie gar nicht unter Vitiligo leiden.

K. MALBERG घ

\section{- Jin, Y et al.}

(Korrespondenzdresse: RA Spritz, University of Colorado Denver, Anschütz Medical Campus, Research Complex 1 North. R. 3107, 128000 East 19th Ave. Mail Stop 8300, Aurora, Colo-rado 80045, USA; E-mail: Richard Spritz@UCDenver.edu) Genome-wide association analyses identify 13 new susceptibility loci for generalized vitiligo. Published online on 06 May 2012 in Nature Genetics 2012; doi:10.1038/ng2272

\section{Impfstoff gegen Meningitis B entwickelt}

\section{Die Meningokokkenmeningitis trifft vor allem Kinder und Jugendliche. Die Erkrankung verläuft in 5-14\% der Fälle tödlich. In Europa und Nord- amerika ist der Meningokokken-Typ-B am weitesten verbreitet. Impfstoffe gibt es bisher jedoch nur gegen die Typen $A$ und $C$.}

- Die Entwicklung eines Impfstoffs gegen den in Europa am weitesten verbreiteten Meningokokkentyp rückt näher. In Phase-2-Studien zeigten Wissenschaftler der University of Western Australia in Cawley (Perth/Australien ) an
Jugendlichen aus Australien, Polen und Spanien, dass der bivalente Impfstoff Antikörper gegen das Oberflächen-Lipoprotein 2086 und den immunogenen Faktor $\mathrm{H}$ der Meningokokken vom Typ B auslöst, ohne schwere Nebenwirkungen zu verursachen.

$80-100 \%$ der Testpersonen zeigten eine Antikörperantwort als Anzeichen für einen Schutz gegen Meningitis. Häufigste Nebenwirkung war ein leichter Schmerz an der Injektionsstelle. Damit könnte es bald möglich sein, sich gegen die europaweit am meisten verbreitete Hirnhautentzündung zu immunisieren.

\section{Kommentar}

Wie lange die Immunität nach der Impfung anhält, ist noch nicht bekant. Dies herauszufinden wird das Ziel der nächsten Studien sein.

K. MALBERG

\footnotetext{
- Taha, M-K et al.

(Korrespondenzadresse: P Richmond, Western Univ Australia, Pediatrics Child Health, School of (SPACH); Cawley, Perth, WA 6009, Australia; E-mail: prichmond@meddent.uwa.edu.au) Vaccines targeting serogroup B meningococci. Published online on 07 May 2012 in Lancet Infectious Diseases 2012; doi: 10.1016/S14733099(12)70093-2
} 